\title{
Omega-3 Fatty Acid
}

National Cancer Institute

\section{Source}

National Cancer Institute. Omega-3 Fatty Acid. NCI Thesaurus. Code C493.

Any fatty acid that contains an unsaturated bond originating from the 3rd carbon from the methyl end. Omega-3 fatty acids do not occur naturally with chain lengths shorter than 16 carbon units. 